Forthcoming in Philosophy and Phenomenological Research

\title{
EMPATHETIC UNDERSTANDING AND DELIBERATIVE DEMOCRACY
}

\author{
Michael Hannon \\ University of Nottingham \\ I have striven not to laugh at human actions, not to weep at them, not to hate them, but to \\ understand them.
}

- Spinoza, Tractatus Politicus

\section{Introduction}

What are the epistemic benefits of democracy? According to the 'epistemic democrats', democratic procedures such as deliberation and voting are valuable in part because they produce epistemically valuable outcomes. Indeed, epistemic democrats claim the legitimacy of democracy depends, at least in part, on the epistemic quality of the outcomes of political decision-making processes. In this paper, I want to consider two epistemic factors that might figure into the value of democracy: veritistic and nonveritistic epistemic goals.

'Veritism' is the view that truth (or accurate belief) is the sole fundamental epistemic value (Goldman 1986). The veritist will thus assess the intellectual virtues, and the epistemic value of institutions and practices, according to how well they promote truth or accuracy. All other epistemic items-such as understanding, reliability, evidence, and open-mindedness-will have value only by tending to produce a high ratio of true to false beliefs, according to the veritist. Veritism is an enduring view upheld by the majority of twentieth-century epistemologists. This view is also endorsed by a variety of so-called 'epistemic democrats'. On the standard interpretation of epistemic democracy, the aim of democracy is to track the truth. ${ }^{1}$ This presupposes a veritistic conception of epistemic value, since the fundamental epistemic goal of democracy is, on this view, reducible to accuracy or truth.

I am sympathetic with the aim of defending democracy on epistemic grounds, but I want to question the standard (veritistic) conception of epistemic value that underpins a lot of work in democratic theory. My

\footnotetext{
${ }^{1}$ See Peter (2016: 133) for a similar characterization.
} 
goal in this paper is to argue that democratic institutions and practices may have epistemic value above and beyond the value of truth or accuracy. To this end, I will outline a version of deliberative democracy that is partly grounded in empathetic understanding. This proposal, if successful, will allow us to expand the range of epistemic goods to which democrats may appeal when arguing for the epistemic value of democracy.

\section{Epistemic Democracy: The Standard Account}

The epistemic value of democracy has been defended by many scholars, perhaps most notably by John Stuart Mill (1977), John Dewey (1939), Karl Popper (1945), and Jürgen Habermas (1983). The view has more recently been taken up by Elizabeth Anderson (2006), Joshua Cohen (1986), David Estlund (2007), Hélène Landemore (2013), Robert Talisse (2010), and Fabienne Peter (2016), and many others. These views differ quite significantly in their details, but they all orbit around the following central idea: unless democracy has epistemic value, there is no adequate case for its legitimacy. I will call this 'the core thesis of epistemic democracy'. Although this thesis is about the grounds that make democracy legitimate, I want to focus on the epistemic value of democracy while leaving aside questions of political legitimacy. That said, epistemic democrats might appeal to the epistemic factors discussed in this paper to further their case for grounding the legitimacy of democracy in epistemic considerations.

As stated, the core thesis of epistemic democracy is neutral with respect to whether democracy's epistemic benefits are veritistic or non-veritistic. The core thesis says that the legitimacy of democracy depends on its epistemic value (or the epistemic quality of the outcomes of democratic processes), but it does not say that these epistemic benefits must be reducible to accuracy or true belief. Nevertheless, the standard conception of epistemic democracy is highly veritistic. ${ }^{2}$ Consider the following remarks:

For epistemic democrats, the aim of democracy is to 'track the truth'. For them, democracy is more desirable than alternative forms of decision-making because, and insofar as, it does that. (List and Goodin 2001: 277; emphasis mine)

Epistemic democrats argue that democratic deliberation is well-suited for tracking the independent truth in moral and technological matters. (Müller 2018: 1268; emphasis mine)

\footnotetext{
${ }^{2}$ Dewey is an exception. On his view, epistemic value is not reducible to truth or knowledge.
} 
[O]n the epistemic interpretation, democratic decision-making processes are valued at least in part for their knowledge-producing potential and defended in relation to this. (Cohen 1986; emphasis mine)

By the standard account I shall denote any characterization of epistemic democracy which centers on the truth-tracking potential of democratic decision-making processes, and in which truth refers to a procedure-independent standard of correctness. (Peter 2008: 33; emphasis mine)

As these passages indicate, the epistemic conception of democracy is standardly characterized in terms of aiming at truth. Joshua Cohen highlights the 'knowledge-producing' (as opposed to truth-tracking) outcomes of democratic decision processes, but it is clear that Cohen is concerned with knowledge in the 'weak' sense of true belief. ${ }^{3}$

The standard (veritistic) conception of epistemic democracy is compatible with both deliberative and aggregative approaches to democracy. Deliberative democrats take deliberation (the exchange of reasons for preferring certain outcomes or believing certain facts) to be central to decision-making. The general idea is that democratic societies allow for freedom of speech, pluralism, free inquiry, open forums, inclusiveness, and other conditions that facilitate the rational deliberation among citizens, and rational deliberation under these conditions allegedly has epistemic benefits. Thus, on the standard conception of deliberative epistemic democracy, the exchange of reasons is said to increase the likelihood that citizens will arrive at the truth. Aggregative democrats, in contrast, claim that the aggregation of individual preferences or beliefs through equally-weighted voting is likely to lead to the truth. $^{4}$

I want to focus specifically on the deliberative conception of democracy. According to John Dryzek (2007: 237), deliberative democracy is "the most active area of political theory in its entirety (not just democratic theory)". This might sound like an exaggeration, but as Diana Mutz (2008: 535) claims, it is "difficult to exaggerate the current enthusiasm for deliberation". Precisely how to define deliberative democracy is a contested issue that I hope to sidestep, but at the heart of all these approaches is the

\footnotetext{
${ }^{3}$ See Goldman (1999: 5) for this distinction between the 'weak' and 'strong' sense of knowledge.

${ }^{4}$ Most deliberative democrats believe that we should eventually aggregate individual preferences (e.g. through voting); they are simply critical of democratic institutional arrangements that rely solely or even primarily on electoral mechanisms. Put another way, the aggregative aspect is not as valuable to deliberative democrats as it is to aggregative democrats. Some go even farther, such as Elster (1986: 112), who says that under deliberation "there would not be any need for an aggregation mechanism, since a rational discussion would tend to produce unanimous preferences".
} 
idea that public reasoning and debate is the cornerstone of democracy. Thus, any epistemic version of deliberative democracy will attribute epistemic value to democratic participation and deliberation.

As mentioned, there are two types of epistemic benefits: veritistic and non-veritistic benefits. There are also two broad ways in which the rational deliberation among citizens can have epistemic benefits: it may have micro-level benefits for individuals (i.e. by making us smarter citizens) and it may have macrolevel benefits for society (i.e. by tending to produce correct decisions or outcomes). ${ }^{5}$ Admittedly, this is a rough distinction; the benefits to individuals may also benefit society, and vice versa. But this distinction is not without merit, for it is possible that an individual will acquire certain epistemic benefits that do not improve the truth-tracking potential of democratic decision-making processes. In what follows, I will focus primarily on the epistemic benefits to individual deliberators, but I will also have something to say about macro-level benefits.

With these clarifications in place, we can now consider the main question of this paper: Does democratic deliberation have epistemic value? If so, for whom?

\section{The Problem of Epistemic Adequacy}

Deliberation is often said to have many benefits for individuals, such as producing tolerance for the views of others, a willingness to compromise, civic engagement, faith in democratic institutions, and making people better citizens overall. ${ }^{6}$ Perhaps the most frequently claimed epistemic benefits of deliberation are: it makes people more informed, makes their views more rational, and alters their preferences and opinions in truth-conducive ways. As J. S. Mill writes, deliberating in public about political issues is good for a democracy because it affords citizens "the opportunity of exchanging error for truth" and the chance of acquiring a "livelier impression of truth" (1859: 21). For Mill, deliberation is a vital mechanism through which individuals improve and develop their political ideas, without which their "mental development is cramped" (ibid: 39).

Yet real life political debates in liberal democracies are often mired in controversy and grounded in nonrational considerations. The evidential basis for policies frequently looks thin, expert opinions are often ignored, and policies bear the marks of political compromise and can be downright irrational (Caplan

\footnotetext{
${ }^{5}$ Following Kuyper (2018), we may also include a third category of group (or meso) benefits. I set these aside.

${ }^{6}$ For a discussion of the benefits to individuals, see Gutmann and Thompson (1996), Mutz (2008), and Mansbridge (1999).
} 
2007 and Huemer 2016). Consider, for instance, the public debate about global warming, which has become distorted by ideological differences. In addition, there is now a sizeable literature, nicely reviewed by Cass Sunstein $(2000,2002)$, indicating that the underlying mechanisms of group deliberation do not provide much reason to think that deliberation fosters epistemic improvement. One of the most well-known group effects of deliberation is that it leads to polarization. In fact, deliberation is known to cause polarization in at least two ways: the first is political polarization, where large sections of the population have consistently divergent views; the second is doxastic polarization, where an epistemically homogeneous group will shift toward a more radical version of its previously held view (i.e. classic group polarization). These are not unrelated phenomenon. Doxastic polarization can lead to political polarization, and political polarization might further exacerbate doxastic polarization.

Polarization raises important normative questions about political deliberation. If deliberation tends to push individuals towards more extreme perspectives, and if groups tend to polarize by growing increasingly divergent from each other, is there any reason to think deliberation will produce epistemic improvement? The empirical evidence does not provide us with much reason for confidence, at least when it comes to moral and political issues. ${ }^{7}$ As Sunstein (2000: 118) maintains, the mechanisms that underlie group polarization cast doubt on the view that deliberation is likely to yield correct answers to social questions.

In addition, a large body of evidence indicates that rational considerations are rarely able to change the minds of others. In The Righteous Mind, for instance, Jonathan Haidt draws on psychological research to argue that people are fundamentally intuitive, not rational. If you want to persuade others, you have to appeal to their sentiments, says Haidt. He defends the Humean view that our desires and passions are not rationally evaluable. In other words, reason cannot tell us what we want, only how to get what we want.

But we needn't be Humeans to doubt the causal efficacy of reasons in our lives. We may grant that, most of the time, people are perfectly capable of being convinced by the best evidence or arguments. After all, there is almost no disagreement over whether antibiotics work or whether heavy drinking impairs people's ability to drive. The problem, as shown by Dan Kahan's excellent work on cultural

\footnotetext{
${ }^{7}$ One might think polarization will occur only in likeminded groups (see Landemore and Mercier 2012). But data from Pew show that engaging in discussion with someone from 'the other side' leads to even wider polarization (see Doherty, Kiley, and Jameson 2016). There are circumstances under which individuals and groups are less likely to polarize; for example, people are less likely to polarize in distinctive settings where trained moderators enforce deliberative norms such as speaking one's mind, listening to others, behaving respectfully. I will discuss this evidence shortly.
} 
cognition, is that people are unlikely to be persuaded by reasons when dealing with issues that threaten their core values or identity. In fact, a lot of empirical work indicates that people become epistemically worse when they deliberate about political issues (Kahan et al. 2011). When we talk about politics, we are especially prone to engage in motivated reasoning, selective recall, identity protection, and a host of other biases and imperfections. We tend to focus on information that confirms our opinions and thereby obstructs our ability to learn from others in deliberation. We also conform our beliefs about highly contested matters to values that define our cultural identities. "The typical citizen", as Joseph Schumpeter puts it, "drops down to a lower level of mental performance as soon as he enters the political field" (1942: 262). Similarly, Jason Brennan (2016) claims that politically engaged people are the most likely to be biased and corrupted by epistemically irrational factors (he calls them 'hooligans'). In cases of deep conflict, even the attempt to deliberate is likely to backfire (Mansbridge 1983). All this goes against Mill's optimistic claim that getting us involved in politics would make us smarter and nobler.

As many critics have noted, epistemic democrats often rely on idealized assumptions about the rationality of deliberators. Discussions of the knowledge-producing potential of liberal democratic deliberation (as well as discussions of rationality in contemporary epistemology) tend to idealize away from the imperfections of actual human psychology. Citizens who deliberate are portrayed as unbiased, open-minded, and persuadable by the "unforced force of the better argument" (Habermas 1983: 132). But cognitive psychology shows that we fall very short of these ideals. This has led many scholars to wonder whether citizens should even be encouraged to deliberate about matters of politics (see Mendelberg 2002).

Some epistemic democrats will admit they are operating with an idealized conception of deliberation. For example, Landemore says her argument for epistemic democracy is

purely a priori and based on an ideal type of what democratic deliberation means and involves. For the argument to translate to real life democracies, more would need to be said than space here allows on whether, and under what conditions, the assumptions can be expected to apply to the real world. (2013: 1210)

It is an open question whether it is wise to work toward the realization of this ideal, even if it can never be achieved. I prefer to consider the effects of deliberation in flesh and blood situations, so I will set aside ideal theory. 
We thus have reason to think democratic deliberation will not improve us epistemically. ${ }^{8}$ Is it possible to defend deliberative democracy on epistemic grounds? We are now left with two options. First, we might abandon the epistemic strategy and defend democracy on other grounds. I will not pursue this option here; this route is well-trodden by the pure proceduralists, who claim that democracy is legitimate not because of its epistemic benefits but rather because it embodies moral values (e.g., equality, dignity, etc.). Instead I want to explore an epistemic version of deliberative democracy that does not succumb to the objections just discussed. To be clear, however, my claim is that deliberation has epistemic value (i.e. can be justified in epistemic terms) in front of other democratic models, particularly those based on pure voting and bargaining. Democratic deliberative procedures are claimed to have more epistemic value than the other democratic alternatives.

\section{Veritism to Verstehenism}

An important question we can ask about collective deliberation is whether it increases the accuracy of the participants' beliefs. But, as Peter (2013) points out, this question does not exhaustively account for the epistemic value that deliberation might have for citizens. We might also consider the epistemic value of democratic deliberation beyond the value of true beliefs. I will argue that public deliberation has epistemic value even when it does not enhance the accuracy of the beliefs of the participants. I am therefore recommending a version of epistemic value pluralism.

In her recent book, True Enough, Catherine Elgin argues that philosophy has wrongly valorized truth. She says the problem with this stance is that it cannot account for the epistemic standing of science, which routinely uses models and idealizations that are known not to be true. Elgin therefore recommends a reorientation in epistemology: we must weaken our commitment to truth and expand our range of epistemic goods. In particular, she advocates shifting epistemology's focus away from the knowledge of

\footnotetext{
${ }^{8}$ There is another, and perhaps deeper, worry for the standard (veritistic) account of epistemic democracy. Fabienne Peter (2016) calls it 'the problem of self-undermining'. On the standard view, there must be a procedureindependent standard for the correctness of outcomes. But the theory will only work if there is someone, or a small group, who has the right to make claims about which democratic decision is correct. In other words, there must be an epistemic authority on the matter to be decided. As Peter points out, however, this makes democratic decision-making either redundant or non-epistemic. Here's why: if we must appeal to those who know what the correct decision is, then our decision-making process is not democratic and also redundant; but if we instead insist on the democratic-decision making process itself, then we cannot defend the legitimacy of democracy on epistemic grounds. Either way, 'epistemic democracy' becomes something of an oxymoron on the standard (veritistic) interpretation. We thus have another reason to question the standard way of conceiving of the relationship between democratic legitimacy and epistemic authority.
} 
individual facts and toward a broader kind of understanding, which is a distinctive epistemic goal that does not reduce to knowledge or truth (Elgin 2017: 2).

I want to advocate for a similar shift in focus. Epistemic democrats have tended to valorize truth, which reflects a way of thinking about epistemic value that has long held epistemologists captive. ${ }^{9}$ Instead of focusing on truth, however, I want to explore a version of epistemic democracy that is grounded in nonveritistic goals. Taking my cue from Elgin, I want to consider the epistemic value of understanding. Unlike Elgin, however, my focus will not be scientific understanding. Rather, I want to focus on the empathetic understanding of others.

In the $19^{\text {th }}$ and $20^{\text {th }}$ centuries, empathy was considered the primary epistemic means for understanding other minds (Stueber 2018). This type of understanding is sometimes called verstehen. Discussion of this notion can be found in German philosophy and the social sciences; in particular, it is present in the work of Max Weber, Georg Simmel, William Dilthey, Johann Gustav Droysen, and Edmund Husserl. Precisely how to define verstehen is a somewhat contested matter, but we may think of it broadly as the empathetic understanding of human behaviour. This sort of understanding is often contrasted with erklaren, or explanation, which is the alleged goal of the natural sciences. To have verstehen is to understand the meaning of an action from the actor's point of view. The general idea is that we can only understand something that has a kind of "inner life" we can enter into.

The role of empathy is largely neglected in studies of deliberation. ${ }^{10}$ In today's political climate, however, empathetic understanding is perhaps more vital than ever. We often hear people say things like "I can't understand why anyone would even think about voting for Brexit" or "I don't understand 'Black Lives Matter'. Don't all lives matter?"11 Citizens are increasingly polarized and political opponents hold highly unfavorable views of each other; indeed, they often regard each other as immoral, stupid, lazy, and even threats to each other's way of life. ${ }^{12}$ We characterize others simplistically, without any appreciation for the nuance or depth of their views, and others do the same to us. As a result, our

\footnotetext{
${ }^{9}$ An epistemic democrat who is committed to veritism need not think the truth is intrinsically valuable. The truth may be instrumentally valuable and yet still the fundamental epistemic good. What is all-things-considered valuable might not bottom out at the epistemic.

${ }^{10}$ Exceptions are Morrell (2010) and Grönlund et al. (2017).

${ }^{11}$ I borrow these examples from Grimm (2018).

12 In 1994, only $16 \%$ of Democrats and 17\% of Republicans held a very unfavorable view of the other party. By 2016, majorities in both parties expressed very unfavorable views of the other party: $58 \%$ Republicans and $55 \%$ Democrats. Also, $45 \%$ of Republicans in 2016 saw policies of the democratic party as "so misguided that they threaten the nation's well being". $41 \%$ of Democrats felt the same about Republican policies. See SinnottArmstrong (2018: 28) and Doherty, Kiley, and Jameson (2016).
} 
attitudes are increasingly antagonistic, not just polarized. We feel hatred, disdain, and fear towards our political opponents. Stephen Grimm (2018) calls this "judgmentalism", which is the tendency to assume others are wicked or malicious. This sort of antagonism is rampant in many countries around the world (Sinnott-Armstrong 2018: 30-1).

A consequence of judgmentalism is that political groups are unable to cooperate and work towards common goals. It is for this reason that mutual understanding is deeply important to social life. As scholars often remark, many of today's societal problems likely stem from a lack of mutual understanding. ${ }^{13}$ Too often political opponents do not even try to understand each other, instead opting for cynicism and contempt. The Internet rewards this sort of behaviour-blogs and tweets go viral when they make fun and ridicule, whereas balanced attempts to see the other side are usually unrewarded (Sinnott-Armstrong 2018). This lack of understanding makes it difficult for us to pursue collective goods. We cannot accomplish anything if we despise each other, refuse to listen, are too overconfident, and lose our willingness to reach a compromise. We must change our basic attitudes towards each other in order to find the common ground on which collective flourishing depends. As Dewey reminds us, "Merely legal guarantees of the civil liberties of free belief, free expression, free assembly are of little avail if in daily life freedom of communication, the give and take of ideas, facts, experiences, is choked by mutual suspicion, by abuse, by fear and hatred" (1939: 342).

\section{What Is Verstehen?}

To understand others, we need to empathize with their thinking. This requires, for a start, that we be willing to listen to them. More than this, however, it requires the ability to "take up" another person's perspective. We must be able to see the other person's point of view. But what does it mean to "take up" the perspective of another person?

One way to think about this is via simulation theory, outlined by Jane Heal (1986) and Alvin Goldman (2006). According to simulationism, we understand others' mental states by trying to place ourselves in their "mental shoes". We reenact the thoughts of another in our own mind by imaginatively assuming his or her own beliefs and desires while temporarily bracketing our own. For example, by imaginatively taking on your desire to get bread and you belief that Waitrose is the best place nearby to get bread, I

\footnotetext{
${ }^{13}$ Sinnott-Armstrong (2018: 5) says a variety of social problems stem from "a lack of mutual understanding". Sunstein (2000) says that polarization and extremism may result from our inability to understand multiple political perspectives.
} 
will come to "see" or appreciate that your trip to Waitrose is the most sensible course of action. Imagination enables us to project ourselves into another situation and think about the world from a different perspective. To use a more relevant example, we might wonder why Harris voted for Trump. To understand why he voted for Trump, we need to identify what Harris took to be desirable or choiceworthy about his goal. In addition, empathetic understanding requires the ability to recognize Harris's goal as a good (from his point of view). Failing that, his actions may be unintelligible to us. As Atticus Finch says in To Kill a Mockingbird, "You never really understand a person until you consider things from his point of view . . . until you climb into his skin and walk around in it". ${ }^{14}$

'Empathetic understanding', or verstehen, should not be equated with all forms of empathy. Following Karsten Stueber (2006), we may distinguish between two types of empathy. Basic empathy is a low-level ability to attribute basic emotions such as fear and anger to others on the basis of their facial expressions. This ability is typically unconscious, automatic, and stimulus-driven. Reenactive empathy, in contrast, involves the use of our cognitive and deliberative capacities to reenact or imitate the thought processes of others. This ability is typically conscious, under voluntary control, and stimulusindependent. The former is a low-level mindreading ability while the latter is a high-level mindreading ability.

To understand a person's behaviour in complex social situations, we need reenactive empathy. Using slightly different terminology, Jason Stanley says that 'cognitive empathy' is central to the democratic ideal. ${ }^{15}$ He writes,

The capacity to be reasonable towards others requires...a disposition to take the perspective of others in the community in proposing reasons, to be empathetic to them, and to respect their dignity. A contribution to public reason is reasonable only if it takes into account the reasonable perspective of all those citizens subject to the policy under debate. (2015: 102)

According to Stanley, the democratic attitude requires the employment of this imaginative capacity. To grasp another person's action as rationally compelling, we must "grasp his thoughts as reasons for acting by putting ourselves in his shoes, by imagining the situation that he faces and trying to reenact his thought processes in our mind" (Stueber 2006: 28). When we understand the point of view of another,

\footnotetext{
${ }^{14}$ Virtue theorists may regard an "understanding person" as someone with a character-level virtue. If this is a virtue, it is an especially needed one in our age of deep political division. I leave open whether or not we should regard verstehen as a character virtue, but the idea is prima facie plausible.

${ }^{15}$ According to Krause (2008), 'cognitive empathy' refers to the process of gaining knowledge about the positions of others, as well as related preferences and values.
} 
we learn what their interests and objectives are, why they think those interests and objectives are worth pursuing, and why they thought their course of action was the right way to pursue them.

This is not to say that empathetic understanding requires us to change our opinions or to stop disagreeing with those we seek to understand. We might continue to disagree, but at least we would understand each other better; and this may help us work together. In contrast, misunderstanding can lead to cynicism and contempt for others, which is part of what causes polarization. To get into an unfamiliar mindset, we must overcome our feelings of condemnation and moral superiority.

Three important caveats are needed. First, it may not always be possible to imaginatively place oneself in the situation of another. As Laurie Paul (2014) claims, it may be impossible to imagine being a person who has had dramatically different life experiences. Second, there may be some people who really are deplorable and morally inferior, and mutual understanding may be unhelpful in these situations. ${ }^{16} \mathrm{My}$ point is just that we're too quick to assume that those who disagree with us are morally or intellectually inferior. Third, our attempts to empathetically understand others may sometimes backfire and exacerbate political polarization. As Olivia Bailey (2018) points out, our inability to make sense of another perspective may naturally incline us to think there is no sense to be gotten. But this inference is dubious because our imaginative abilities are subject to impairments that may have nothing to do with the sensibility or accuracy of the point of view we are trying to understand. For example, it is much easier for us to imaginatively adopt the perspective of someone who is part of our social 'in-group' (Hoffman 2001:197-219). Thus, our attempts to understand others should be coupled with an epistemically humble attitude where one thinks: "whether or not I can imaginatively get myself to a version of the other's attitude has no bearing on whether her attitude is correct" (Bailey 2018: 156).

I have been describing empathetic understanding as a form of simulation, but this is not the only way to model our understanding of others. There is also abundant evidence that people use narratives to make sense of their lives (McAdams 2008). As Matthew d'Ancona writes,

\footnotetext{
${ }^{16}$ In 'The Epistemology of Terrorism and Radicalisation,' Quassim Cassam recommends that we try to empathetically understand why individuals turn to political violence. But I worry that attempting to understand extremists might be dangerous. It is difficult for us to sustain an empathetic representation without regarding that perspective as to some degree appropriate (see Bailey 2018). For example, my discovery that I empathize with my colleague's frustration about some issue will incline me to think that she is right to feel frustrated. Likewise, my discovery that I understand and empathize with a terrorist might incline me towards terrorism. I take this to be a very bad result. Indeed, it might be a moral failing that one is able to successfully project oneself into some truly horrific outlooks.
} 
For most of human history, shared mythologies and tribal stories have done more to explain human behavior than the cool assessment of verifiable evidence. Every society has its founding legends that bind it together, shape its moral boundaries and inhabit its dreams of the future. Since the Scientific Revolution and the Enlightenment, however, these collective narratives have competed with rationality, pluralism and the priority of truth as a basis for social organization. (2017: 31)

In general, we assimilate information by fitting it to narrative templates that invest the information with meaning. Consider the slogan "Make American great again!" These four words manage to suggest a narrative about a thriving American past, a nation in decline, and a desire for revival. It appeals to many people because it fits into the way they already understand the world. Thus, understanding our fellow citizens may require us to focus on the narratives people live by. These narratives are rarely true, of course. But we should ask why certain claims feel true to many people. By trying to fit people's actions with a coherent narrative, we may come to understand them better.

\section{The Political Turing Test}

Suppose we do successfully adopt the perspective of someone who disagrees with us. We still face an epistemological problem, namely, how do we know (or have justified beliefs about) whether we've understood their view?

A useful heuristic is what Bryan Caplan (2011) calls the 'political turing test' ${ }^{17}$ The political turing test adapts an idea proposed by Alan Turing in 1950, who created a test to assess whether a computer had achieved human-like intelligence. ${ }^{18}$ Instead of testing a machine's ability to imitate a human, however, the political turing test is used to assess a human's ability to correctly understand the viewpoint of his or her intellectual adversary. It works like this: a partisan individual is invited to answer questions (or write an essay) posing as his or her ideological opponent. If a neutral judge (or perhaps even a political adversary) cannot tell the difference between the partisan's answers and the answers of his or her political opponent, the candidate is judged to correctly understand the opposing perspective. Thus, a Democrat who says that Republicans voted for Donald Trump "because they are stupid" would

\footnotetext{
${ }^{17}$ Caplan actually calls this the 'ideological turing test', but I prefer my label in the context of this paper.

${ }^{18}$ The original Turing Test is basically this: a human (the judge) attempts to tell if they're having a written conversation with a computer or another human, and if the judge cannot reliably tell whether they are interacting with a computer or a human, then the computer must be a passable simulation of a human being and, hence, intelligent.
} 
obviously fail the test. Likewise, a Republican who claims that Democrats voted for Hillary Clinton "because they're elitist" would also fail. An added benefit of the political turing test is that we can assess the merits of our own views by better understanding those who disagree with us. As Mill reminds us, "He who knows only his own side of the case knows little of that."

The test is not a perfect criterion for understanding others, but it does prevent us from idly speculating about whether partisans understand each other. Further, it allows us to measure the performance of someone who boasts about understanding his or her opponents. Once we come to understand the perspectives of people on the other side of the ideological spectrum, we can begin to have a sensible discussion about what divides us. This is perhaps the first step to overcoming the ideological cleavages that inhibit cooperation and stifle progress.

\section{Empirical Support}

It is an important empirical question whether deliberation, under the right conditions, will foster empathetic understanding. I have not tested this hypothesis, but there is some promising evidence to support it.

In 'Empathy in a Citizen Deliberation Experiment', Kimmo Grönlund and colleagues ran a deliberative experiment to examine the role of empathy in citizen deliberation. They were specifically interested in (a) whether the capacity to consider the perspectives of others is a precondition for deliberation, and (b) to what extent deliberation improves this capacity (Grönlund et al. 2017: 457). Their findings suggests that deliberating in ideologically mixed groups increases outgroup empathy.

The study was designed to compare deliberation among likeminded people (enclave deliberation) with deliberation in cross-cutting groups. It involved three stages. First, a random sample of citizens was surveyed for their opinions on immigration. Second, these individuals were divided into a 'permissive' or 'non-permissive' enclave (based on their opinions about immigration), and then randomly assigned into likeminded or mixed-opinion groups for deliberation. Third, they were surveyed anew after deliberation. The aim of the study was to analyze empathy differences between permissive and non-permissive participants, as well as to look at changes in outgroup empathy towards immigrants as a result of deliberation. The results show that "the permissive respondents had more empathy, especially toward 
immigrants, than the non-permissive respondents" (Grönlund et al. 2017: 457). Further, outgroup empathy was shown to increase during deliberation. ${ }^{19}$

Admittedly, this experiment took place in a fairly controlled environment. The group discussions lasted for four hours, including a 45 minute lunch break. In each small group, trained moderators facilitated the discussion and a written description of the rules of the discussion was handed out to the participants in the beginning. These rules emphasized respect for the opinions of others, the importance of justifying one's own opinions, and openness to other points of view (Grönlund et al. 2017: 467). Thus, citizens may need encouragement to display attitudes conducive to empathy and not open hostility. This shouldn't be surprising. If deliberation naturally led to mutual understanding, we would expect far less polarization and antagonism than currently exists in many societies. My claim is not that empathetic understanding is easy or that it will naturally result from discussing politics with people from diverse perspectives. ${ }^{20}$ Rather, I claim that mutual understanding ought to be a conscious goal of democratic deliberation and (more controversially) that it should often take priority over other deliberative goals, such as reasoned argumentation that aims at truth. ${ }^{21}$ I'll elaborate on this idea in the next section.

There is also abundant empirical evidence, surveyed in Morrell's Empathy and Democracy, to support the importance of empathetic understanding in political deliberation. Morrell draws on literature about group polarization, individual biases, and a variety of other areas to defend the claim that "in order to decrease biases and polarization, and increase cooperation and reciprocity, deliberators must demonstrate predispositions to both perspective taking and empathetic concern" (2010: 126). For example, empirical studies show that we humans have a tendency to attribute relatively negative motives to people whose attitudinal and political positions differ from our own (Reeder et al 2005). Put differently, we attribute negative motives to people with whom we disagree; this makes it difficult to

\footnotetext{
${ }^{19}$ Mendelberg and Oleske (2000) found that discussion did not produce greater tolerance for opposing views, but Kuyper (2018) argues that this work suffers from a methodological bias, namely, it was reliant upon participants' self-assessment for measures of empathy. Recent studies that rely upon more objective measures (e.g., Siu 2008) are more promising.

${ }^{20}$ It is more difficult for us to adopt an empathetic attitude towards members of socially more distant groups than those people who are similar or close to us (see Cikara et al. 2014 for references).

${ }^{21}$ Diana Mutz (2002) provides evidence that exposure to diverse political views produces greater tolerance and greater awareness of the rationales for oppositional political views, without needing trained moderators or written rules of politeness. In a similar study, Diana Mutz and Jeffery Mondak (2006) found consistent evidence that crosscutting political discussion in the workplace increases people's knowledge of rationales for political perspectives and fosters political tolerance. Tolerance is not the same things as empathetic understanding, of course. Tolerance, as I understand it, is more about putting up with people whose ideas we reject. This falls short of empathetic understanding, but it may facilitate our ability to better understand the basis of political conflict and also increase our appreciation of the rights and perspectives of people with whom we disagree.
} 
reach any sort of mutual understanding. Morrell thus cites numerous studies demonstrating that empathetic understanding "increases the likelihood that people will have less negative, or even more positive, evaluations of out-groups [and their members]" (2010: 101-114). ${ }^{22}$ It would be needlessly redundant to summarize the data surveyed in Morrell's book, so I will simply refer you to his chapter titled 'Empathy's Importance-the Empirical Evidence'.

This research provides evidence that empathetic understanding is vital for deliberative democracy to function as envisioned by its defenders, since people from different cultural backgrounds are unlikely to reach an agreement unless they work to understand each other's perspectives. As Morrell puts it,

[W]ithout the process of empathy, it is highly unlikely that citizens will demonstrate the toleration, mutual respect, reciprocity, and openness toward others vital for deliberative democracy to fulfil its promise of equal consideration that is central to giving collective decisions their legitimacy. (2010: 114-5)

A goal of deliberative democratic systems should therefore be to encourage citizens to empathetically understand others. How might they do this? I can only hint at two strategies here. One option is to include empathy as part of democratic education (Morrell 2007; McGregor 2004). In doing so we can aim at increasing citizens' capacities for perspective taking and empathetic concern. Another option, proposed by Goodin (2003: 189-92), is to try to induce empathy through presentations in literature, film, and other arts that can encourage citizens to be empathetically sensitive. A famous example is Harriet Beecher Stowe's Uncle Tom's Cabin, a book that fuelled the Abolitionist movement by helping people imagine what it might like to be a slave (see Goodin 2003: 8). Policies that support a diffusion of the arts throughout society can aid empathetic understanding in deliberation. Further, this is more practical than having citizens in large-scale societies meet face-to-face with each other. ${ }^{23}$

\section{Empathetic Understanding, Not Reasoned Argumentation}

I do not mean to suggest that deliberative democrats are against the idea that we should attempt to empathetically understand those with whom we disagree. Indeed, proponents of deliberative democracy typically argue that "inclusive and authentic deliberation will lead to deeper understanding

\footnotetext{
22 Inducing citizens to adopt an empathetic and understanding perspective may also lead to what Gutmann and Thompson call "moral accommodation" (1996: 79-91).

${ }^{23}$ As Robert Goodin (2003: 171) notes, empathetic understanding may be triggered by a form of internal, reflective deliberation that takes place within the minds of citizens. It does not require face-to-face interaction.
} 
and appreciation of the views of others" (Kuyper 2018: 8). But instead of regarding empathetic understanding as the result of rational deliberation, we might better think of it as a precondition for the kind of rational process standardly envisioned by deliberative theorists.

As Mercier and Landemore (2012: 246) point out, most deliberative democrats embrace the classical Aristotelian definition of deliberation as "an exchange of arguments for or against something" (Aristotle, Rhetoric, I, 2). Mendelberg (2002: 153) call this process "reasoned argumentation". It involves weighing the available data, arguing about relevance and worthiness, and then choosing the best policy or person (see Walzer 1999: 58). This is problematic, however, because too much focus on rational argument may actually prevent us from achieving a deep understanding of each other. Simply sharing our experiences is a rich form of conversation because it can help our interlocutor see the world from our perspective. Our aim needn't be to find the truth or persuade others to switch sides. When I ask my brother why he likes reading video game magazines, I hold no hope that he will convince me of their value. Rather, I just want to understand him better.

Instead of requiring deliberation to be based on reasons and principles, I am suggesting a more expansive view of deliberation. ${ }^{24}$ Being too concerned with reasoned argumentation will likely thwart our ability to empathetically understand other perspectives. When political discourse aims to persuade others, we often become further entrenched in our views and are epistemically worse off as a result. This form of political engagement rarely develops our critical thinking skills or increases our knowledge. Quite the opposite. Attempting to persuade others via reasoned argumentation often has instrumental epistemic disvalue because it hinders the formation of accurate beliefs. If we start by trying to understand each other, rather than to convince one another, then we are more likely to appreciate various conceptions of the good life. As Catherine Elgin (unpublished ms) nicely puts it, "Rather than seeing those who disagree with us as opponents, we should see them as potential allies who, by envisioning things differently, extend our epistemic range".

This is not to say we should never try to change someone's mind through debate. Certainly there is value in using arguments founded on good reasons to support and defend our political views. But I am doubtful that we should expect rational argument to change the minds of others when they have deeply

${ }^{24}$ Iris Marion Young has also argued for the inclusion of alternative forms of communication, apart from rational argumentation. By limiting deliberation to impartial and rational forms of argumentation, she fears this will favour white middle-class men who already dominate politics (in the US). In reply, one might argue that these alternative forms of communication do not qualify as deliberation; but the scope of deliberation is highly contested and up for grabs (see Macedo 1999). As Mutz (2008: 525) notes, there is "a great deal of conceptual ambiguity as to what should qualify as deliberation." 
held political views, at least when people deeply disagree and fail to understand each other's perspective. The hope is that empathetic understanding will open up space for more fruitful deliberation. ${ }^{25}$

\section{Is Verstehen Epistemically Counterproductive?}

This proposal may strike you as epistemically counterproductive ${ }^{26}$ In place of rationally discussing substantive moral and political issues, I seem to be recommending that we first think about the psychology of the deliberators, not the logical perspicuity of their argument. This may seem epistemically counterproductive because it could erode the quality of the debate by distracting people from the moral and political issues we care more about. Further, in many cases it may be more difficult to adequately understand a person's perspective than it would be to focus on the arguments themselves. As Kornblith (1999: 191) observes, "we have little access to the information we would need to understand fully a person's motivations, at least unless we know the individual extremely well". Indeed, there may be cases in which the deliberator herself does not understand why she holds a particular view. She may think she knows when she is actually engaging in rationalization. Her deeper motives may be hidden from introspection.

I accept these practical difficulties in attempting to understand other people. If the sources of an individual's view are numerous and idiosyncratic, then empathetic understanding may require a great deal of knowledge or be practically infeasible. But these obstacles do not arise in all cases. There are cases in which a person's motivation in offering an argument is entirely transparent. As Kornblith writes, suppose that instead of these sources' being varied and idiosyncratic, there are a very small number of sources of significant distortion and rationalization. Let us suppose, indeed, that there is a single major source of distortion and rationalization that is very widespread. Thus, for example, Marxists have suggested that class interests form just such a source of distortion and

\footnotetext{
${ }^{25}$ That said, there might be times when empathetic understanding requires us to not deliberate at all. In a study of cross-cutting political discussion in the workplace, Diana Mutz and Jeffery Mondak (2006) found consistent evidence that people become more politically tolerate and achieve a greater awareness of the rationales for oppositional views simply by listening to their co-workers talk about their political views. Few would call this deliberation, but understanding the benefits that derive from listening to others is central to understanding the benefits of the deliberative process as a whole.

${ }^{26}$ Kornblith (1999: 285) considers a similar objection against the so-called 'skeptics about reason'. This section draws heavily on his discussion.
} 
rationalization; some feminists have suggested that the interests of male domination play such a role. (Kornblith 1999: 192-3)

Supposing that some such hypothesis is correct, then empathetic understanding would not be practically infeasible. Sometimes we may not need to know much about a particular individual in order to have some sense of his or her motivations and worldview. Once we have come to understand the social factors at work in society at large, the epistemic task of understanding them may not be too difficult (ibid). A public debate on some issue might be largely shaped by a single (or few sources of) bias that is extremely likely to come into play and overwhelm the discussion when certain members of the community are present.

\section{The Benefits of Verstehen}

Understanding the viewpoints of people who disagree with us will have many benefits.

First, increasing mutual understanding will likely reduce various forms of polarization, especially affective polarization (i.e. animosity towards one's political opponents). In the United States, most Democrats and Republicans hold very unfavourable views of each other, and these negative attitudes likely stem from a lack of understanding. It is easy to feel contempt for views we don't really understand, which deepens political divides. To bridge political gaps and make progress, we must be able to find common ground. This requires the ability to arrive at a shared understanding of the world. ${ }^{27}$

Second, empathetic understanding will make it easier for us to reap the benefits of cognitive diversity. According to Landemore (2013) and many others, the inclusion of a diversity of perspectives has epistemic value. But for diverse groups to function in practice, the people in them must be able to get along. ${ }^{28}$ After all, we cannot deliberate well when we view the other side with animosity and contempt. But, as we know from experience and empirical studies, people who disagree about politics often do not get along. Without empathetic understanding, intergroup disagreement will likely undermine the epistemic quality of deliberation. Thus, rather than erode the quality of debate (as suggested in the

\footnotetext{
${ }^{27}$ By attempting to understand others, we also we treat them as rational agents. As R.G. Collingwood (1946) and Dray (1995) claim, re-enacting another person's thoughts is necessary for understanding them as rational agents. In contrast, a lack of understanding breeds contempt, which leads us to view those who disagree with us as irrational, misinformed, tribalistic, etc.

${ }^{28}$ This point is made by Scott Page (2010), Mercier and Sperber (2017), and Jason Brennan (2016).
} 
previous section), verstehen may actually improve it. By changing our attitudes towards each other, we may enhance our ability to engage each other in rational and fruitful discussion.

Third, appreciating the other side's perspective may help us to exit 'echo chambers'. People are increasingly clustering into communities - both on and offline-where they talk only to those with whom they already agree. Bill Bishop (2008) calls this 'the big sort'. We choose to live, work, and socialize more with people like ourselves in every way. Further, we tend to process information about outgroup members in extreme, black-and-white, simplistic ways (Linville and Jones 1980). This likely explains why we view our political opponents as close-minded, immoral, lazy, dishonest, and unintelligent, which reinforces our desire to interact only with those who share our worldview. But this prevents us from understanding contrary viewpoints. Were we to empathetically understand those who do not share our values, we would not view them with such antipathy. This would allow us to become more enlightened about the needs and experiences of other people, which may help us to resolve deep conflicts.

That said, leaving our echo chambers might have a surprising consequence: we may become less politically engaged.

One of the central findings of Diana Mutz's work is that participatory democracy is at odds with deliberative democracy. More specifically, her research shows that exposure to diverse perspectives and deliberating with people who hold contrary views tends to make citizens ambivalent and apathetic about politics. As a result, they are less likely to participate in politics (Mutz 2006: 120). In contrast, the most politically active citizens rarely talk to people who have different opinions and they tend to be worse at explaining the rationale behind contrary viewpoints. In other words, the most politically active citizens are the least likely to pass the political turing test. The more time we spend in our echo chambers, the more likely we are to be politically active. This goes against the received wisdom that citizens who take part in open-minded deliberation will, as a result, be more active in politics (Mendelberg 2002: 153-4).

I will leave open whether decreased participation in political life would be a bad thing or not. That is a complicated question. For now, I will simply point out that many theorists think less political engagement would not be all that bad. For example, in his new book Overdoing Democracy, Robert Talisse argues that politics is too pervasive in modern liberal democracies and that we would largely 
benefit from "putting politics in its place". In Against Democracy, Brennan likewise suggests that fewer participants in politics would make us better off.

\section{Is Verstehen an Epistemic Good?}

Verstehen might be vital for a healthy democracy, but is it an epistemic good? Perhaps it is a moral good because it reduces disdain for others and helps us resolve deep conflicts, but this does not prove that empathetically understanding others has epistemic value.

I think verstehen combines both moral and epistemic elements. On the moral side, there is an important connection between empathetic understanding and moral goods like peace, love, and tolerance. As Ralph Waldo Emerson says, "Peace cannot be achieved through violence, it can only be attained through understanding." Similarly, followers of John Rawls often talk about something similar to understanding others, but their focus is mainly on respect and the discussion is about moral (as opposed to epistemic) goods.

But a lack of empathetic understanding also has epistemic drawbacks. If we are too quick to deplore, rather than work to understand others, we will "misportray their psychological profiles and moral standing" (Grimm 2018: 345). This is because we will be "too quick to attribute wicked or malicious motives" to them when in fact more ordinary motives and faults are called for (ibid). Further, one who is unable to understand diverse perspectives will exhibit a variety of epistemic vices, such as closemindedness, dogmatism, self-deception, and superficiality of thought. ${ }^{29}$ As Grimm (2018: 346) points out, these epistemic drawbacks will likely exist alongside traditionally moral faults, such as excessive self-satisfaction and arrogance, as well as the inability to appreciate one's own moral frailty. Plausibly, we also display 'intellectual courage' by seeking to understand perspectives that challenge our own worldview.

Empathetic understanding will also facilitate rational deliberation, especially on political and moral issues. We cannot have a reasonable and open-minded discussion if we despise each other, refuse to listen, and are too overconfident in our own views. Changing our attitudes toward each other therefore has epistemic payoffs. In this way, empathetic understanding is of instrumental epistemic value. Indeed,

\footnotetext{
${ }^{29}$ Studies show that we tend to process information in less sophisticated ways when it comes from people we regard as unlike us. Thus, empathetic understanding may improve our information processing by making people who hold radically different views to us seem less foreign or alien.
} 
it may even increase our ability to track the truth on various moral and political issues. After all, a more compassionate and understanding view of others might be truth-conducive-who knows?

Does this imply that empathetic understanding has epistemic value only in relation to the truth? In other words, have I provided a genuine alternative to veritism?

Perhaps we cannot escape the truth entirely. ${ }^{30}$ After all, I have said that empathetic understanding will help us more accurately portray the psychological profiles and moral standing of other people. But even if empathetic understanding requires true beliefs of some sort, it does not require us to track the independent truth on moral and political issues. Put differently, the epistemic value of deliberation needn't reside solely, or even primarily, in reaching accurate judgments on matters of policy. This is still a genuine alternative to the standard (veritistic) account of deliberative democracy. According to the standard view, public deliberation has epistemic value because it leads citizens to hold more accurate beliefs and opinions on the relevant policy issues. I have argued, however, that public deliberation may have epistemic (and moral) value even when it does not enhance the accuracy of our views on these matters. We may come to "see" or appreciate why an individual or group regards a particular course of action as the most sensible even when it is false that it is the most sensible. Thus, democratic deliberation can be said to have epistemic value when it fosters empathetic understanding, even though this value is not understood in relation to the discovery of an independently existing correct outcome.

Can we provide a genuine alternative to veritism, not just an alternative to the standard veritistic account of deliberative democracy? I think so. For example, there may be cases in which we continue to misportray the psychological profiles and moral standing of other people, and yet the mere attempt to understand other perspectives will lead us to be less dogmatic, more open-minded, and less superficial in our own thinking. In this way, the empathetic attitude may work against a variety of epistemic vices whether or not one has accurately understood the target perspective.${ }^{31}$ Relatedly, we can imagine individuals with accurate but highly unjustified true beliefs about some political matter; in these cases, empathetic understanding may lead them to appreciate alternative perspectives even when it diminishes the accuracy of their view. Imagine, for instance, that Sheela has been raised by elitist parents who have taught her that epistocracy is better than democracy, Suppose for the sake of argument that epistocracy is overall preferable to democracy. Still, we might want people like Sheela to

\footnotetext{
30 I just wrote a book that reduces epistemic value to true beliefs (see Hannon 2019).

${ }^{31}$ Admittedly, the virtues of open-mindedness and being undogmatic may generally be good because they foster true beliefs, but we needn't think they do so in every case.
} 
adopt an empathetic attitude, even if it diminishes the accuracy of their beliefs, because it works against a kind of doxastic complacency or laziness in belief formation.

Ultimately, however, it does not much matter to me whether empathetic understanding escapes veritism entirely. What matters is the role it ought to play in democratic deliberation.

\section{Conclusion}

As I have argued, the epistemic value of democracy may be evaluated in veritistic or non-veritistic terms. The standard characterization of epistemic democracy centers on its truth-tracking potential, which presupposes veritism. According to some deliberative conceptions of epistemic democracy, engaging in democratic deliberation allegedly makes citizens smarter by improving the accuracy of their views. In Mill's words, it affords citizens "the opportunity of exchanging error for truth" (1859: 21). However, it seems that people may actually become epistemically worse when they deliberate about politics.

While I am sympathetic with the idea that deliberation has epistemic benefits, I have questioned whether we should conceive of these epistemic goods primarily in terms of tracking the independent truth in moral and political matters. Public deliberation may have epistemic value even when it does not enhance the accuracy of these beliefs. This is not to say we should give up on the goal of truth. Acknowledging the existence and importance of non-veritistic epistemic goods does not require us to abandon the goal of truth and replace it with something else. I am simply suggesting that we expand the range of epistemic goods to which theorists may appeal in defense of epistemic democracy. To this end, I have outlined an epistemic version of deliberative democracy that is grounded in the empathetic understanding of others.

Acknowledgement. Thanks to Elizabeth Edenberg for thoughtful and detailed comments on an earlier draft. 


\section{Bibliography}

Anderson, E., 2006. 'The Epistemology of Democracy.' Episteme 3 (1-2): 8-22.

Bailey, O. 2018. 'Empathy and Testimonial Trust.' Royal Institute of Philosophy Supplement 84: 139-160.

Bishop, B. and Cushing, R., 2008. The Big Sort. New York: Houghton Mifflin.

Brennan, J., 2016. Against Democracy. Princeton: Princeton University Press.

Caplan, B., 2011. The Ideological Turing Test. URL =

https://www.econlib.org/archives/2011/06/the_ideological.html

Caplan, B., 2007. The Myth of the Rational Voter. Princeton: Princeton University Press.

Cassam, Q., 2018. 'The Epistemology of Terrorism and Radicalisation.' Royal Institute of Philosophy Supplement 84: 187-209.

Christiano, T., 1996. The Rule of the Many. Boulder, CO: Westview Press.

Cikara, M., Bruneau, E., Van Bavel, J. J., \& Saxe, R., 2014. 'Their pain gives us pleasure: How intergroup dynamics shape empathic failures and counter-empathic responses.' Journal of Experimental Social Psychology 55: 110-125.

Cohen, J., 1986. 'An epistemic conception of democracy.' Ethics 97(1): 26-38.

Collingwood, R.G., (1946) 1994. The Idea of History. London: Oxford University.

d’Ancona, M., 2017. Post Truth. Random House

Dewey, J., (1939) 1998. The Essential Dewey (Vol. 1): Pragmatism, Education, and Democracy. Indiana University Press.

Doherty, C., Kiley, J. and Jameson, B., 2016. 'Partisanship and political animosity in 2016.' Washington, DC: Pew Research Center.

Dray, W.H., 1999. History as re-enactment: RG Collingwood's idea of history. Clarendon Press.

Dryzek, J.S., 2007. 'Theory, evidence, and the tasks of deliberation. 'In Deliberation, participation and democracy (pp. 237-250). Palgrave Macmillan, London.

Elgin, C., Unpublished MS. 'Deweyan Democratic Deliberation.' 
---. 2017. True Enough. MIT Press.

Elster, J., 1986. 'The Market and the Forum: Three Varieties of Political Theory.' In Foundations of social choice theory, edited by J. Elster and A. Hyland, 103-132. Cambridge: Cambridge University Press.

Estlund, D., 2007. Democratic Authority: A Philosophical Framework. Princeton: Princeton University Press.

Grimm, S., 2018. 'Understanding as an Intellectual Virtue.' In The Routledge Handbook of Virtue Epistemology. Ed. Heather Battaly. London: Routledge.

Goldman, A., 2006. Simulating Minds. Oxford University Press.

---. 1999. Knowledge in a Social World. Oxford University Press.

---. 1986. Epistemology and Cognition. Harvard University Press.

Goodin, R.E., 2003. Reflective Democracy. Oxford University Press.

Grönlund, K., Herne, K. and Setälä, M., 2017. 'Empathy in a Citizen Deliberation Experiment.' Scandinavian Political Studies 40(4): 457-480.

Gutmann, A. and Thompson, D.F., 1996. Democracy and disagreement. Harvard University Press. Habermas, J., 1983. Moral Consciousness and Communicative Action. C. Lenhardt and S.W. Nicholsen (trans). Cambridge, MA: MIT Press.

Haidt, J., 2012. The righteous mind: Why good people are divided by politics and religion. Vintage. Hannon, M., 2019. What's the Point of Knowledge? Oxford University Press.

Heal, J., 1986. 'Replication and functionalism.' In Jeremy Butterfield (ed.), Language, Mind, and Logic. Cambridge University Press. pp. 135--150.

Hoffman, M., 2001. Empathy and Moral Development: Implications for Caring and Justice. Cambridge University Press.

Huemer, M., 2016. 'Why People Are Irrational About Politics.' In: Jonathan Anomaly, Geoffrey Brennan, Michael Munger, and Geoffrey Sayre-McCord (eds.), Philosophy, Politics, and Economics. New York: Oxford University Press. 
Kahan, D.M., Jenkins-Smith, H. and Braman, D., 2011. 'Cultural cognition of scientific consensus.' Journal of Risk Research 14(2): 147-174.

Kelsen, H., 1955. 'Foundations of democracy.' Ethics 66(1, Part 2): 1-101.

Kornblith, H., 1999. 'Distrusting reason.' Midwest Studies in Philosophy 23(1): 181-196.

Krause, S. E., 2008. Civil Passions: Moral Sentiment and Democratic Deliberation. Princeton: Princeton University Press.

Kuyper, J.W., 2018. 'The Instrumental Value of Deliberative Democracy-Or, do we have Good Reasons to be Deliberative Democrats?' Journal of Public Deliberation 14(1): 1-35.

Landemore, H., 2013. 'Deliberation, cognitive diversity, and democratic inclusiveness: an epistemic argument for the random selection of representatives.' Synthese 190(7): 1209-1231.

Landemore, H., \& Mercier, H., 2012. 'Talking It Out With Others vs. Deliberation Within and the Law of Group Polarization: Some Implications of the Argumentative Theory of Reasoning for Deliberative Democracy.' Análise Social XLVII (205): 910-934.

Linville, P.W. and Jones, E.E., 1980. 'Polarized appraisals of out-group members.' Journal of Personality and Social Psychology 38(5): 689-703.

List, C. and Goodin, R. 2001. 'Epistemic Democracy: Generalizing the Condorcet Jury Theorem.' Journal of Political Philosophy 9 (3): 277-306.

Macedo, S. ed., 1999. Deliberative politics: Essays on democracy and disagreement. Oxford University Press.

Mansbridge, J., 1999. 'On the idea that participation makes better citizens.' In S. Elkin and K. Soltan (ed.), Citizen competence and democratic institutions. University Park: Pennsylvania State University Press, 291-325.

---. 1983. Beyond Adversary Democracy. University of Chicago Press.

McAdams, D.P., 2008. 'Personal narratives and the life story.' Handbook of personality: Theory and research 3: 242-262.

McGregor, C., 2004. 'Care(full) Deliberation: A Pedagogy for Citizenship.' Journal of Transformative Education 2(2): 90-106. 
Mendelberg, T., 2002. 'The deliberative citizen: Theory and evidence.' Political decision making, deliberation and participation 6(1): 151-193.

Mendelberg, T. and Oleske, J., 2000. 'Race and public deliberation.' Political Communication 17(2): 169191.

Mercier, H. and Sperber, D., 2017. The enigma of reason. Harvard University Press.

Mercier, H. and Landemore, H., 2012. 'Reasoning is for arguing: Understanding the successes and failures of deliberation.' Political Psychology 33(2): 243-258.

Mill, J. S., 1977. Essays on Politics and Society. Collected Works Vol. 18. Ed. J.M. Robson. Kegan \& Paul. ---. (1859) 1956. On Liberty. Ed. C.V. Shields. Bobbs-Mer

Morrell, M.E., 2010. Empathy and democracy: Feeling, thinking, and deliberation. Penn State Press.

---. 2007. 'Empathy and Democratic Education.' Public Affairs Quarterly 21(4): 381-403.

Müller, J. F. 2018. 'Epistemic democracy: beyond knowledge exploitation.' Philosophical Studies 175 (5): $1267-1288$.

Mutz, D.C., 2008. 'Is deliberative democracy a falsifiable theory?' Annu. Rev. Polit. Sci. 11: 521-538.

---. 2002. 'The consequences of cross-cutting networks for political participation.' American Journal of Political Science 46(4): 838-855.

Mutz, D.C. and Mondak, J.J., 2006. 'The workplace as a context for cross-cutting political discourse. The Journal of Politics 68(1): 140-155.

Page, S.E., 2010. Diversity and complexity. Princeton University Press.

Paul, L.A., 2014. Transformative experience. Oxford University Press.

Peter, F., 2016. 'The Epistemic Circumstances of Democracy.' In Michael S. Brady and Miranda Fricker (Eds.) The Epistemic Life of Groups. Oxford University Press, 133-149.

---. 2013. 'The procedural epistemic value of deliberation.' Synthese 190: 1253-1266.

---. 2008. 'Pure epistemic proceduralism.' Episteme 5(1): 33-55.

Popper, K., 1945. The Open Society and Its Enemies (2 Volumes). London: Routledge. 
Reeder, G. D., Pryor, J. B., A., M. J., \& Griswell, M. L. 2005. 'On Attributing Negative Motives to Others Who Disagree With Our Opinions.' Personality and Social Psychology Bulletin 31(11): 1498-1510.

Schumpeter, J., 1942. Capitalism, Socialism, and Democracy. New York: Harper.

Sinnott-Armstrong, W., 2018. Think Again. Penguin.

Siu, A. 2008. Look who's talking: Examining social influence, opinion change, and argument quality in deliberation. Palo Alto, CA: Stanford University.

Stanley, J., 2015. How propaganda works. Princeton University Press.

Stueber, K. 2018. 'Empathy.' The Stanford Encyclopedia of Philosophy. Edward N. Zalta (ed.), URL = https://plato.stanford.edu/archives/spr2018/entries/empathy/

---. 2006. Rediscovering empathy. Cambridge, MA: The MIT Press.

Sunstein, C., 2002. 'The law of group polarization.' Journal of political philosophy 10(2): 175-195.

---. 'Deliberative Trouble? Why Groups Go To Extremes.' Yale Law Journal 110: 71-119.

Talisse, R., 2019. Overdoing democracy. Princeton University Press.

---. 2010. 'An epistemological defense of democracy.' Critical Review 22(2-3): 281-291.

Walzer, M., 1999. On toleration. Yale University Press. 